\title{
Steady State Numerical Simulation of Natural Gas Cleaning Process
}

\author{
Marwa Ahmed Khodary*, Yousra Hamdy Farid \\ Basic Science Department, Alexandria Higher Institute of Engineering \& Technology (AIET), Alexandria, Egypt \\ Email address: \\ dr.marwa.khodary@gmail.com (M. A. Khodary), dr.yousra.hamdy@aiet.edu.eg (Y. H. Farid) \\ ${ }^{*}$ Corresponding author
}

To cite this article:

Marwa Ahmed Khodary, Yousra Hamdy Farid. Steady State Numerical Simulation of Natural Gas Cleaning Process. American Journal of Applied Chemistry. Vol. 9, No. 1, 2021, pp. 1-5. doi: 10.11648/j.ajac.20210901.11

Received: December 16, 2020; Accepted: January 8, 2021; Published: January 22, 2021

\begin{abstract}
Natural gas is a promising elective source of methane $\left(\mathrm{CH}_{4}\right)$ due to its accessibility and renewability. However, unfortunately, a high rate of carbon dioxide $\left(\mathrm{CO}_{2}\right)$ and very little hydrogen sulfide $\left(\mathrm{H}_{2} \mathrm{~S}\right)$ is found in this $\mathrm{CH}_{4}$ source. These compounds must be removed to get natural gas of satisfactory quality. One of the most modern common strategies of synchronous $\mathrm{CO}_{2}$ and $\mathrm{H}_{2} \mathrm{~S}$ removal is chemical absorption, i.e. the use of a Pressure Swing Absorber (PSA). In order to design an efficient plant, the characteristic acidic gas treating plant is mimicked utilizing Aspen HYSYS 8.8. The point of this mimicry is to attain the methane immaculateness of the natural gas by determining the optimum working pressure using a Pressure Swing Absorber (PSA) in which the feed sour gas is fed to the absorber at a concentration of $0.25 \mathrm{CO}_{2}$ and 0.0004 $\mathrm{H}_{2} \mathrm{~S}$. The absorber parameters are: $30^{\circ} \mathrm{C}$ (temperature), 1.1 bars (initial pressure) and $15 \mathrm{~m}^{3} / \mathrm{h}$ (stream rate), and $25 \mathrm{wt} . \%$ monoethanolamine (MEA) concentrate. A 20-stage PSA with a tray diameter of $1.7 \mathrm{~m}$ is used. The results of the study show that in order to obtain natural gas with a methane purity of $95 \%$, a PSA working pressure of 5 bars is needed.
\end{abstract}

Keywords: Natural Gas Purification, Methane Upgrading, Aspen HYSYS, Chemical Absorption

\section{Introduction}

Natural gas refinement is a method in which $\mathrm{CO}_{2}$ and $\mathrm{H}_{2} \mathrm{~S}$ are evacuated in arrangement to secure the pipelines arrangement from acidic impact [1]. The composition of natural gas is subordinate to the source of the biomass from which it is produced. In this work, it was expected that crude common gas is utilized to get methane from plantations. [2]. A Pressure Swing Adsorption (PSA) is the most utilized procedure for natural gas updating. In (PSA) forms, natural gas is compressed to a pressure between $4-10$ bars and is delivered to a vessel (column) where it is put in contact with a fabric (adsorbent) that will specifically hold $\mathrm{CO}_{2}$. The adsorbent could be permeable, strong, and ordinarily with a tall surface region. Most of the adsorbents utilized within he commercial forms are carbon molecular sieves (CMS), however actuated carbons, zeolites and other materials (titanosilicates) are utilized as well. The filtered $\mathrm{CH}_{4}$ is recuperated towards the upper end of the column with quite a low pressure drop. After a specific amount of time, the adsorbent is immersed with $\mathrm{CO}_{2}$, and the column is recovered by reducing the pressure (to vacuum for natural gas upgrading). The adsorption of $\mathrm{H}_{2} \mathrm{~S}$ is regularly irreversible within the adsorbents, and hence a process to dispense with this gas ought to be carried out some time before the PSA [3]. The most compelling parameters which can influence the entire plant productivity are channel gas and dissolvable temperature, as their decrease increases the amount of retention and rich amine stacking and cooling water prerequisite. Absorber pressure, solvent flow-rate and concentration can increment the physical assimilation rate. However, the dissolvable circulation rate is the most vital parameter to be considered regarding the working capital required for the plant [4].

But the primary and first parameter to design the plant is the type of solvent used. There are a few amine solvents with various interesting merits as well as drawbacks. [5] Right now, the most commonly utilized dynamic components for the previously stated retention in the mechanical aspect are amines, wealthuding monoethanolamine (MEA), diethanoloamine (DEA), methyldiethanolamine (MDEA), 
and diglycolamine (DGA). Their behavior within the chemical retention preparation mentioned above is examined $[2,6-8]$. It has been decided that a 50-70 mass \% of DGA aqueous solutions are not only capable to retain a specified $\mathrm{CO}_{2}$, but also capable of obtaining the required $\mathrm{H}_{2} \mathrm{~S}$ specification. On the other hand, a 20-50 mass \% of MDEA aqueous solutions have a low-heat response compared to other amine solutions, and the selectivity towards the response with $\mathrm{H}_{2} \mathrm{~S}$ takes off a huge amount of $\mathrm{CO}_{2}$ in the vaporous stage. Moreover, utilizing MDEA leads to a comparatively lower solution loss. Hence, in spite of other amines being way better suited for the refinement of expansive sums of $\mathrm{CO}_{2}$, the impact of MDEA expansion in other fluid amine solutions is explored. [9, 10] The rate of $\mathrm{CO}_{2}$ retention into watery MEA, MDEA, and MEA/MDEA solutions has been the subject of investigation. Also, fluid $\mathrm{PZ} /$ potassium carbonate $\left(\mathrm{K}_{2} \mathrm{CO}_{3}\right)$ blends have been examined. $[11,12]$

The adsorption isotherms of $\mathrm{CH}_{4}$ and $\mathrm{CO}_{2}$ on silica gel are calculated tentatively on a settled bed, stuffed with silica gel. Reenactment results demonstrate that the mimicked biogas may be isolated to an improved $\mathrm{CH}_{4}$ stream at $98.01 \% \mathrm{CH}_{4}$ immaculateness and $97.31 \% \mathrm{CH}_{4}$ recuperation, as well as a concentrated stream of $\mathrm{CO}_{2}$ at $96.74 \% \mathrm{CO}_{2}$ virtue as well as

\subsection{8\% $\mathrm{CO}_{2}$ recuperation. [13]}

Computer-supported programs play an imperative part within the plan of filtration cycles. [14] This paper aims at planning a characteristic gas handling plant to benefit from the methane required for the specifications of the networks used in providing residential natural gas. [15]

In order to fulfill this aim, an Aspen HYSYS simulation program is utilized to decide on the ideal PSA (Weight Swing Absorber) working pressure arrangement to attain the most elevated methane immaculateness from natural gas. Monoethanolamine (MEA) dissolvable with a concentration of 0.3 wt. $\%$ is utilized to remove the $\mathrm{CO}_{2}$ and $\mathrm{H}_{2} \mathrm{~S}$ at the same time from the feed natural gas of the total volume stream rate of around $15 \mathrm{~m}^{3} / \mathrm{h}$. into a 20 -stage (PSA). It has been proven that 5 bar is the optimum PSA working pressure required for the production of pure $99 \%$ methane from the Egyptian biogas.

\section{Methodology}

Figure 1 portrays the normal total corrosive gasses expulsion cycle (sweetening cycle) which is registered in the Aspen HYSYS 8.8 library and is utilized for natural gas NG upgrading and decontamination [15] in which the corrosive gas evacuation steps are carried out. [16]

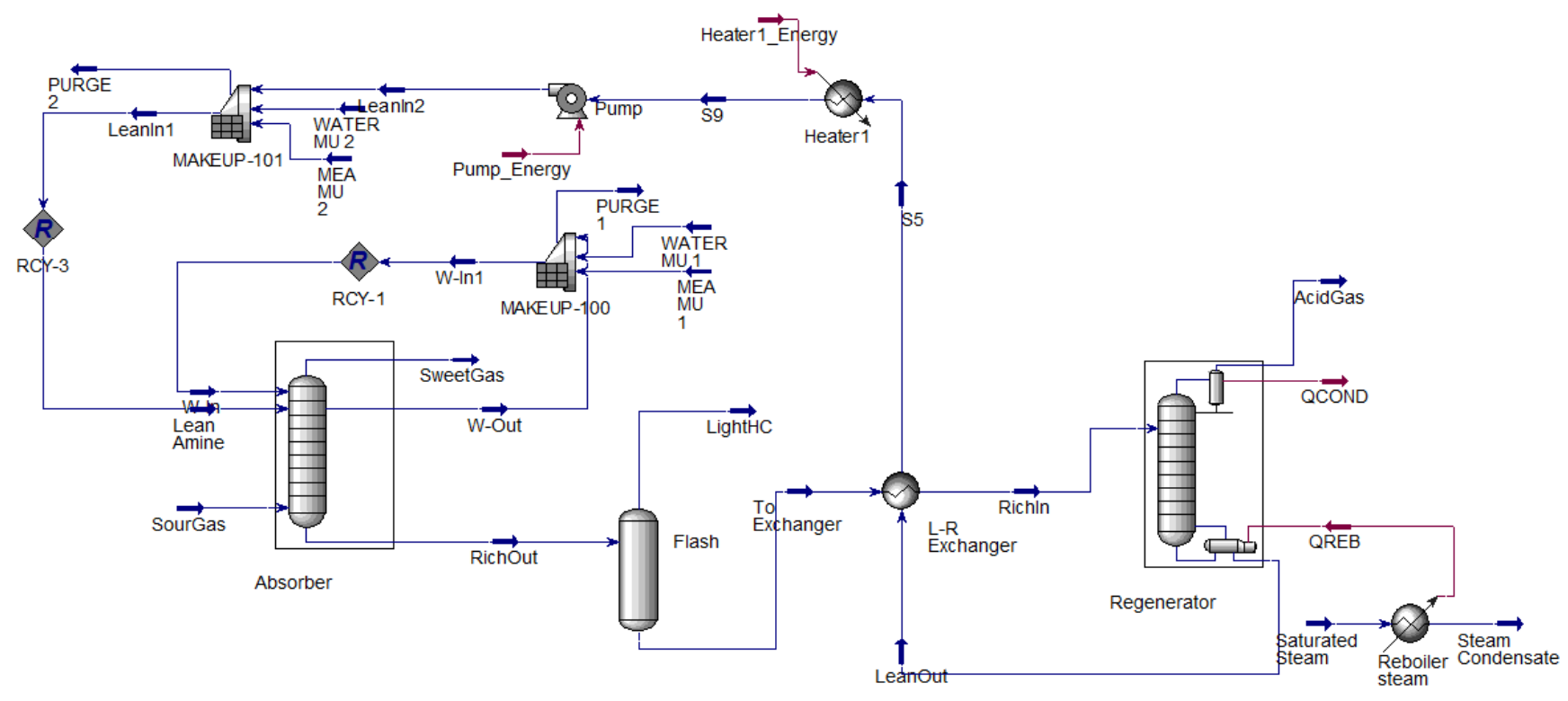

Figure 1. Main Natural Gas Cleaning Cycle with (MEA).

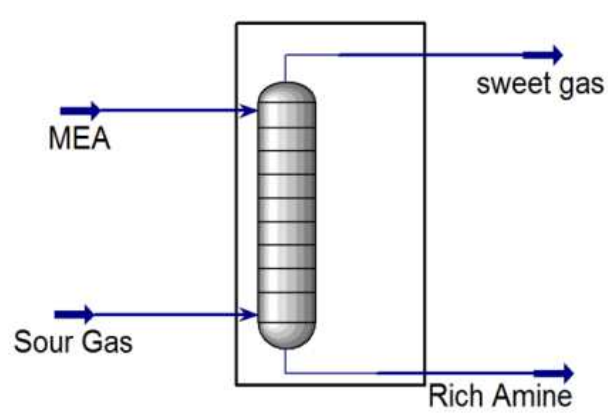

Absorber

The absorber column chosen from Aspen HYSYS shows the bed as it appears in Figure 2, which has an inner column consisting of 20 stages, each arrangement is comprised of a single plate with a development that resembles a strainer. The corrosive gas liquid bundle containing MEA is additionally chosen [17].

The feed natural gas which has the composition illustrated in Table 1 enters the absorber at a temperature of $30^{\circ} \mathrm{C}$, a pressure of 1.1 bar and a volume stream rate of $15 \mathrm{~m}^{3} / \mathrm{h}$ from the lower part of the absorber column. The ethanolamine (MEA) enters at the upper part of the column with the following parameters: $30^{\circ} \mathrm{C}, 20$ bars and $5.45 \times 10^{-4} \mathrm{~m}^{3} / \mathrm{h}$. The

Figure 2. Main cycle absorber column. 
amine MEA retains $\mathrm{CO}_{2}$ and $\mathrm{H}_{2} \mathrm{~S}$ from the feed natural gas at the same time. The sweet feed gas, devoid of $\mathrm{CO}_{2}$ and $\mathrm{H}_{2} \mathrm{~S}$, exits from the upper part of the column, and the enriched amine exits from the lower part of the absorber. At that point, the enriched amine transfers through the development valve to grow to $43^{\circ} \mathrm{C}$ and 1.4 bars, and after that it passes to the separator.

Rich amine comes out from the separator with the same previously mentioned parameters to pass to a lean amine/ rich amine warm exchanger (L/R).

The $(\mathrm{L} / \mathrm{R})$ heat exchanger changes warmth from the lean amine to the rich amine. The hot, rich amine coming out from the exchanger passes to a recovery column to extricate $\mathrm{CO}_{2}$ from the rich amine to lean it for reuse, whereas the lean amine passes to a make-up tank at $74^{\circ} \mathrm{C}$ and 1.04 bar which has the pressure of 0.027 bar and comes out from it at above $74^{\circ} \mathrm{C}$ and 1.04 bars which rise to the same channel conditions of the make-up tank. At that point, it is pumped to $74.5^{\circ} \mathrm{C}$ and 1.1 bars progressively and it is cooled at consistent weight handle to $30^{\circ} \mathrm{C}$ to be sent to a reuse. Lean amine comes out from reuse at $30^{\circ} \mathrm{C}$ and 1.1 bars [18].

Table 1. Feed Egyptian Natural Gas Composition.

\begin{tabular}{lll}
\hline Component & Mole fraction & Volume fraction \\
\hline Methane $\left(\mathrm{CH}_{4}\right)$ & 0.7464 & 0.7466 \\
Carbondioxide $\left(\mathrm{CO}_{2}\right)$ & 0.2522 & 0.2522 \\
Hydrogen Sulphide $\left(\mathrm{H}_{2} \mathrm{~S}\right)$ & 0.0004 & 0.0004 \\
Water vapour $\left(\mathrm{H}_{2} \mathrm{O}\right)$ & 0.0004 & 0.0004 \\
Hydrogen $\left(\mathrm{H}_{2}\right)$ & 0.0001 & 0.0001 \\
Nitrogen $\left(\mathrm{N}_{2}\right)$ & 0.0002 & 0.0002 \\
Oxygen $\left(\mathrm{O}_{2}\right)$ & 0.0003 & 0.0003 \\
\hline
\end{tabular}

\section{Result and Discussion}

The reenactment cycle is created to safeguard the transformation by utilizing Aspen HYSYSA 8.8 for PSA the optimized working pressure. All the numerical reenactment parameters of temperatures, pressure and feed gas stream rates of the evacuation cycle are a result of running various reenactment trials in arrangement to induce the most noteworthy methane immaculateness from natural gas.

\subsection{Effect of Natural Gas PSA Working Pressure on the Final $\mathrm{CO}_{2}$ Content Product}

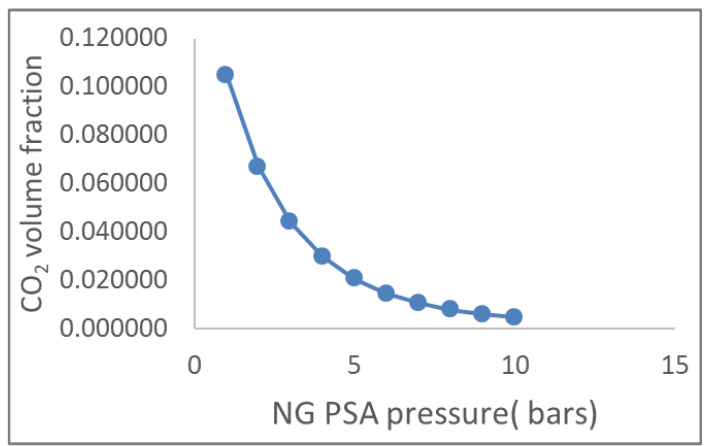

Figure 3. Effect of Natural gas PSA working pressure on the final $\mathrm{CO}_{2}$ content product.
Figure 3 illustrates that there is an inverted proportion between PSA working weight and $\mathrm{CO}_{2}$ volume division within the natural gas last item gas. At this point, which is the absorber PSA working pressure of 5 bar, the $\mathrm{CO}_{2}$ volume division rises to 0.020540 . When the pressure rises to more than 5 bar, a small impact of PSA working pressure on the $\mathrm{CO}_{2}$ contents is created. Thus, it is unnecessary to raise the PSA working pressure to more than 5 bar in order to preserve the ideal start for absorber development.

\subsection{Effect of Natural gas PSA Working Pressure on Natural Gas Final Product $\mathrm{H}_{2} \mathrm{~S}$ Contents}

Figure 4 shows that there is also a reverse extent between PSA working pressure and $\mathrm{H}_{2} \mathrm{~S}$ volume fraction within the natural gas final product. The $\mathrm{H}_{2} \mathrm{~S}$ content can be expelled totally from natural gas output at a pressure of 5 bar. It is thus concluded that the pressure of 5 bar is the one required to clean $\mathrm{H}_{2} \mathrm{~S}$ from natural gas.

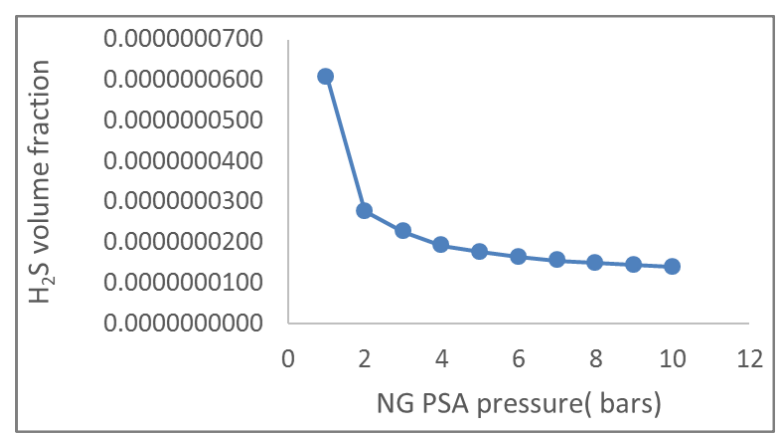

Figure 4. Effect of Natural gas PSA working pressure on Natural gas final product $\mathrm{H}_{2} \mathrm{~S}$ content.

\subsection{Effect of Natural Gas PSA Working Pressure on Methane Purity of the Natural Gas Final Product}

Figure 5 illustrates the impact of the PSA working pressure on the methane purity of the final natural gas product. At this point, which is the absorber PSA working pressure of 5 bar, the methane purity reaches around 95\%; the required rate of most NG systems. There is a higher impact of PSA working pressure on the methane purity if by chance the pressure is raised to more than 5 bar.

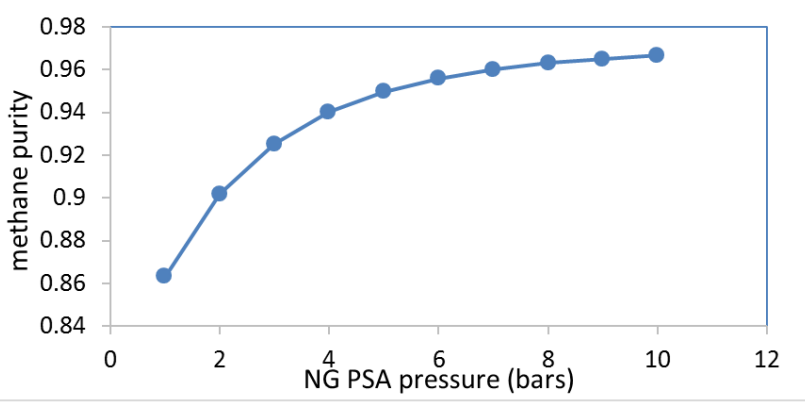

Figure 5. Effect of natural gas PSA working pressure on natural gas final methane purity product.

From the curves above which depict the connection 
between PSA working pressure and methane purity for natural gas, it is clear that the optimum pressure, which is required to realize the demanded methane purity from natural gas, equal to $95 \%$, is 5 bar. In case the pressure is less than that estimation, the natural gas treating cycle can create methane of less purity. Based on Amagat's Law of added substance volume which bargains with partial volume [19], the fractional volume of a specific gas in a blend is the volume of one component of the gas blend. The partial pressure of the acidic gasses is demonstrated in Table 2.

$$
V_{x=} V_{t o t} \times \frac{p_{x}}{p_{t o t}}
$$

At the same total volume, there is a direct proportion between $V_{x}$ and the term $\left(p_{x} / p_{\text {tot }}\right)$; thus, if the term $\left(p_{x} / p_{\text {tot }}\right)$ is very small, then the term $V_{x}$ is very small too. This means that Amagat's Law of additive volume clearly justifies the fact that any rise in total pressure can raise the methane purity.

Table 2. Partial pressure of $\mathrm{CO}_{2}$ and $\mathrm{H}_{2} \mathrm{~S}$ in natural gas.

\begin{tabular}{ll}
\hline Acidic Component & Partial Pressure \\
\hline $\mathrm{CO}_{2}$ partial pressure & 0.2774 bar \\
$\mathrm{H}_{2} \mathrm{~S}$ partial pressure & $4.455 \times 10^{-4} \mathrm{bar}$ \\
\hline
\end{tabular}

The ideal PSA working pressure required for natural gas cleaning of acidic gasses is 5 bars. The ultimate composition of sweetening gas, which is extracted from natural gas, is mentioned in Table 3.

Table 3. Composition of final sweetening natural gas.

\begin{tabular}{lll}
\hline Component & Mole Fraction & Volume Fraction \\
\hline Methane $\left(\mathrm{CH}_{4}\right)$ & 0.9556 & 0.9784 \\
Carbondioxide $\left(\mathrm{CO}_{2}\right)$ & 0.0084 & 0.0086 \\
Hydrogen & & \\
Sulphide $\left(\mathrm{H}_{2} \mathrm{~S}\right)$ & 0 & 0 \\
Water vapour $\mathrm{r}\left(\mathrm{H}_{2} \mathrm{O}\right)$ & 0.0352 & 0.0121 \\
Hydrogen $\left(\mathrm{H}_{2}\right)$ & 0.0001 & 0.0001 \\
Nitrogen $\left(\mathrm{N}_{2}\right)$ & 0.0003 & 0.0003 \\
Oxygen $\left(\mathrm{O}_{2}\right)$ & 0.0004 & 0.0004 \\
\hline
\end{tabular}

\subsection{Effect of Natural Gas Feed Temperature on the Methane Purity}

Figure 6 demonstrates that there is a reverse relation between natural gas feed temperature and methane purity. The most effective feeding temperature is from $(20$ to 25$){ }^{\circ} \mathrm{C}$ when the methane purity reaches around $91 \%$.

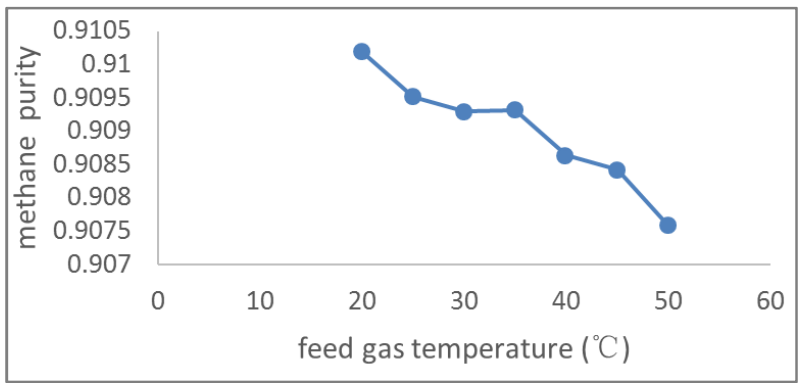

Figure 6. Effect of natural gas feed temperature on the methane purity.

\subsection{Effect of MEA Concentration on Natural Gas Final Product Methane Purity}

Figure 7 reveals the impact of the MEA concentration on the methane purity of the natural gas final output. When MEA concentration values are from (0-20 wt. \%), the methane purity rate is steady. When the MEA concentration rate increases from ( 20 to $25 \mathrm{wt}$. \%), the methane purity rises up to $99 \%$. However, after the MEA concentration rises from 25 wt. $\%$, the methane purity is steady again.

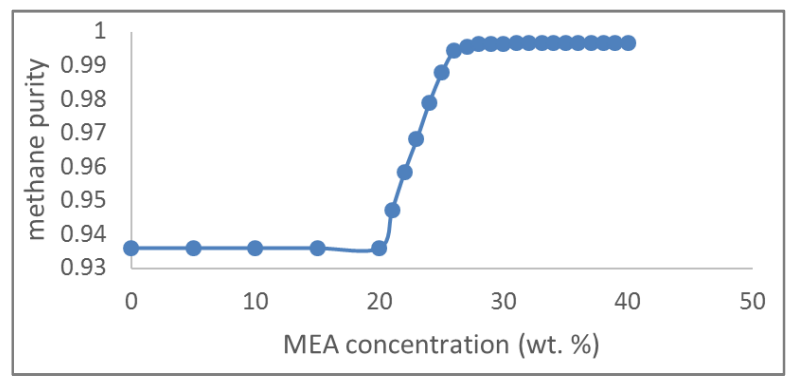

Figure 7. Effect of MEA concentration on methane purity.

\subsection{Effect of E-glycol \% on Final Product Methane Purity}

The glycol dehydration process is an absorption dehydration process in which a liquid desiccant is utilized to absorb water from the gas stream. Ethylene glycol $\left(\mathrm{HOCH}_{2} \mathrm{CH}_{2} \mathrm{OH}\right)$ is the principal chemical agent in this process, as it is a very strong absorbent of water. When it comes in contact with a stream of water-wet natural gas, the ethylene glycol absorbs the water from the gas stream [20].

Figure 8 shows the effect of E-glycol \% on the methane purity of the natural gas final product. It is observed that the percentage of E-glycol is directly proportional to the natural gas final product methane purity.

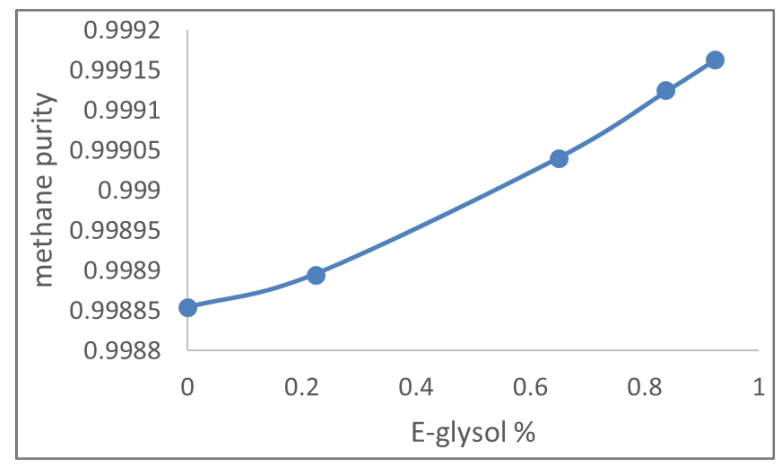

Figure 8. Effect of E-glycol\% on the methane purity

\section{Conclusion}

The aim of the study is to yield the highest possible methane purity from the natural gas of Egypt. The sour gas is fed to the PSA with the $\mathrm{CO}_{2}$ concentration of $0.25, \mathrm{H}_{2} \mathrm{~S}$ of 0.0004 , at temperature $30^{\circ} \mathrm{C}$, an initial pressure of 1.1 bars, and a flow rate of $15 \mathrm{~m}^{3} / \mathrm{h}$. An MEA solvent, of varying concentrations, is utilized to extract the $\mathrm{CO}_{2}$ and $\mathrm{H}_{2} \mathrm{~S}$ one after the other. The numerical simulation reveals that the best parameters for the 
natural gas cleaning process are created by using Monoethanolamine (MEA) with a concentration of 0.3 and 20 -stage PSA with a tray diameter of $1.7 \mathrm{~m}$. The optimum Pressure Swing Absorber working pressure (PSA) is determined by a numerical simulation using Aspen HYSYS simulation software. It is concluded that 5 bar is the most efficient PSA working pressure value required to extract $95 \%$ pure methane from the examined natural gas.

\section{Nomenclature}

$\begin{array}{ll}\text { Cond } & \text { Condenser } \\ \text { MEA } & \text { Monoethanolamine } \\ \text { L/R } & \text { Lean/Reach } \\ \text { NG } & \text { Natural gas } \\ \text { PSA } & \text { Pressure Swing Absorber } \\ \text { Ptot } & \text { Total pressure of the gas mixture } \\ \text { Px } & \text { Partial pressure of an individual gas component }(X) \text { in the mixture } \\ \text { RCY } & \text { Recycler } \\ \text { REB } & \text { Reboiler } \\ \text { VLV } & \text { Valve } \\ \text { Vtot } & \text { Total volume of the gas mixture } \\ \text { Vx } & \text { Partial volume of an individual gas component }(X) \text { in the mixture }\end{array}$

\section{References}

[1] Helsing, G. P., Options for Carbon Capture with Storage or Reuse in Waste Incineration Processes. 2015.

[2] VO, T. T., Wall, D. M., Ring, D., Rajendran, K., \& Murphy, J. D. (2018). Techno-economic analysis of biogas upgrading via amine scrubber, carbon capture and ex-situ methanation. Applied energy, 212, 1191-1202.

[3] Sahota, S., Shah, G., Ghosh, P., Kapoor, R., Sengupta, S., Singh, P., \& Thakur, I. S. (2018). Review of trends in biogas upgradation technologies and future perspectives. Bioresource Technology Reports, 1, 79-88.

[4] Rogelj, J., McCollum, D. L., O’Neill, B. C., \& Riahi, K. (2013). 2020 emissions levels required to limit warming to below $2^{\circ} \mathrm{C}$. Nature Climate Change, 3 (4), 405-412.

[5] Wang, M., Joel, A. S., Ramshaw, C., Eimer, D., \& Musa, N. M. (2015). Process intensification for post-combustion $\mathrm{CO}_{2}$ capture with chemical absorption: A critical review. Applied Energy, 158, 275-291.

[6] Saha, D., Grappe, H. A., Chakraborty, A., \& Orkoulas, G. (2016). Postextraction separation, on-board storage, and catalytic conversion of methane in natural gas: a review. Chemical Reviews, 116 (19), 11436-11499.

[7] Afkhamipour, Morteza, and Masoud Mofarahi. "Review on the mass transfer performance of $\mathrm{CO}_{2}$ absorption by amine-based solvents in low-and high-pressure absorption packed columns." RSC advances 7.29 (2017): 17857-17872.

[8] Borhani, T. N. G., Azarpour, A., Akbari, V., Alwi, S. R. W., \& Manan, Z. A. (2015). $\mathrm{CO}_{2}$ capture with potassium carbonate solutions: a state-of-the-art review. International Journal of Greenhouse Gas Control, 41, 142-162.

[9] Ghiasi, M. M., Arabloo, M., Mohammadi, A. H., \& Barghi, T. (2016). Application of ANFIS soft computing technique in modeling the $\mathrm{CO}_{2}$ capture with MEA, DEA, and TEA aqueous solutions. International Journal of Greenhouse Gas Control, 49, 47-54.
[10] Zhao, B., Su, Y., Tao, W., Li, L., \& Peng, Y. (2012). Post-combustion $\mathrm{CO}_{2}$ capture by aqueous ammonia: A state-of-the-art review. International Journal of Greenhouse Gas Control, 9, 355-371.

[11] Plaza, Jorge M., David Van Wagener, and Gary T. Rochelle. "Modeling $\mathrm{CO}_{2}$ capture with aqueous monoethanolamine." Energy Procedia 1.1 (2009): 1171-1178.

[12] Hasan, M. F., First, E. L., Boukouvala, F., \& Floudas, C. A. (2015). A multi-scale framework for $\mathrm{CO}_{2}$ capture, utilization, and sequestration: CCUS and CCU. Computers \& Chemical Engineering, 81, 2-21.

[13] Jiang, N., Shen, Y., Liu, B., Zhang, D., Tang, Z., Li, G., \& Fu, B. (2020). $\mathrm{CO}_{2}$ capture from dry flue gas by means of VPSA, TSA and TVSA. Journal of $\mathrm{CO}_{2}$ Utilization, 35, 153-168.

[14] Saadabadi, S. A., Thattai, A. T., Fan, L., Lindeboom, R. E., Spanjers, H., \& Aravind, P. V. (2019). Solid Oxide Fuel Cells fuelled with biogas: Potential and constraints. Renewable Energy, 134, 194-214.

[15] Rao, K. Nagamalleswara, and A. Babu Ponnusami. "SIMULATION STUDIES ON NATURAL GAS SWEETENING USING PIPERAZINE AMINE." Petroleum \& Coal 60.4 (2018).

[16] Ubam, U. S., U. D. Amoka, and I. Shaibu. "Simulation of a process plant for production of benzene, toluene and xylene from liquified petroleum gas." Niger. J. Eng. Sci. Technol. Res 4.1 (2018): 37-45.

[17] King, Ralph. Safety in the process industries. Elsevier, 2016.

[18] Abdulrahman, Ahmed Osama, and Donald Huisingh. "The role of biomass as a cleaner energy source in Egypt's energy mix." Journal of cleaner production 172 (2018): 3918-3930.

[19] Wang, Jianlong, and Can Chen. "Biosorbents for heavy metals removal and their future." Biotechnology advances 27.2 (2009): 195-226.

[20] James G. Speight PhD, DSC, in Deep Shale Oil and Gas, "Properties Processing of Gas from Tight Formations", (2017): 307-347. 